Conference Paper

\title{
Broken bar fault diagnosis for induction machines under load variation condition using discrete Wavelet transform
}

Shi, P., Chen, Z., Vagapov, Y., Davydova, A. and Lupin, S.

This is a paper presented at the 12th IEEE East-West Design and Test Symposium EWDTS 2014, Kiev, 26-29 September, 2014.

Copyright of the author(s). Reproduced here with their permission and the permission of the conference organisers.

\section{Recommended citation:}

Shi, P., Chen, Z., Vagapov, Y., Davydova, A. and Lupin, S. (2014), 'Broken bar fault diagnosis for induction machines under load variation condition using discrete Wavelet transform', in: Proc. 12th IEEE East-West Design and Test Symposium EWDTS 2014, Kiev, 26-29 September, 2014, pp. 152-155. doi: $\underline{\text { 10.1109/EWDTS.2014.7027059 }}$ 


\section{Broken Bar Fault Diagnosis for Induction Machines under Load Variation Condition using Discrete Wavelet Transform}

\author{
$\mathrm{Pu}$ Shi, Zheng Chen, Yuriy Vagapov \\ Glyndwr University, \\ Plas Coch, Mold Road, \\ Wrexham, LL11 2AW, UK
}

\author{
Anastasia Davydova, Sergey Lupin \\ National Research University of \\ Electronic Technology, \\ Zelenograd, Moscow, 124498, Russia
}

\begin{abstract}
The paper presents a new approach for detection of broken rotor bar fault in squirrel cage induction motors operating under varying load conditions. A mathematical model used in the presented method was developed using winding function approach to provide indication references for induction motor parameters under load variation. The model shows a strong relationship between broken rotor bar fault and stator current. The method is based on analysis of stator current using discrete wavelet transform. To verify the proposed method a squirrel cage induction motor with 1, 2 and 3 broken bars at no-load, half- and full-load conditions was investigated. Obtained experimental results confirmed the validity of the proposed approach.
\end{abstract}

\section{Introduction}

Accurate and prompt on-line fault detection and diagnosis (FDD) of induction machines improves safety and reliability of industrial processes. Recent investigations regarding induction motor reliability have revealed that $19 \%$ of the total motor faults are related to the rotor part [1].

Variety of methods, such as short time Fourier transform (STFT) [2], high resolution frequency estimation [3], and signal demodulation (SD) technique [4] have been proposed and developed to reduce the effect of the non-periodicity and non-stationary on the analysed signals. All above mentioned techniques are based on fast Fourier transform (FFT) and provide high quality discrimination between healthy and faulty conditions. However, FFT based approaches can not show fault evolution information in time domain. Wavelet analysis, which provides greater resolution in time for high frequency components and greater resolution in frequency for low frequency components, has been proposed to overcome this shortcoming.

Since the emergence of wavelet analysis, this method has been used with different approaches for the diagnosis of rotor anomalies in induction machines such as wavelet ridge method [5] or wavelet coefficients analy- sis [6]. Following up these steps, approximations and details signals were investigated for reproducing the instantaneous evolution of rotor fault frequency components [7] and quantifying the fault extents [3]. However, the majority of these methods track rotor fault frequency components on multi frequency bands, which make the diagnosis processes complicate.

This paper proposes a new broken rotor bar fault diagnostic method for diagnosis of squirrel cage induction motors. This method is based on discrete wavelet coefficients and applicable for induction motors operating under varying load conditions. In this paper, winding function approach (WFA) was used to develop a mathematical model to provide indication references for parameters under load variation. Stator current was used to demonstrate the relationship between this parameter and broken rotor bar severity.

\section{Model of three phase induction machine}

To study the amplitude variation of currents, speed and torque components, WFA based coupled circuits model which accounts for all the space harmonics in the machine is adopted as shown in Fig. 1 [8].

The model of the induction motor is considered using the following assumptions: the air-gap is uniform and smooth; the magneto motive force (MMF) distribution in the air-gap is sinusoidal; the rotor bars are insulated from the rotor and there is no inter-bar current flows through the laminations; the permeability of machine armatures is assumed infinite; the eddy current, friction, windage losses, saturation and skin effect are neglected [8].

The mathematical model for the induction machine can be written as:

$$
\begin{aligned}
& {\left[V_{s}\right]=\left[R_{s}\right]\left[I_{s}\right]+\frac{d}{d t}\left[\Phi_{s}\right]} \\
& {\left[V_{r}\right]=\left[R_{r}\right]\left[I_{r}\right]+\frac{d}{d t}\left[\Phi_{r}\right]}
\end{aligned}
$$

where $\left[V_{s}\right],\left[V_{r}\right],\left[I_{r}\right],\left[R_{s}\right],\left[R_{r}\right],\left[\Phi_{s}\right],\left[\Phi_{r}\right]$ are matrices that represent voltage, currents, resistance and flux linkage of the stator and rotor respectively. 


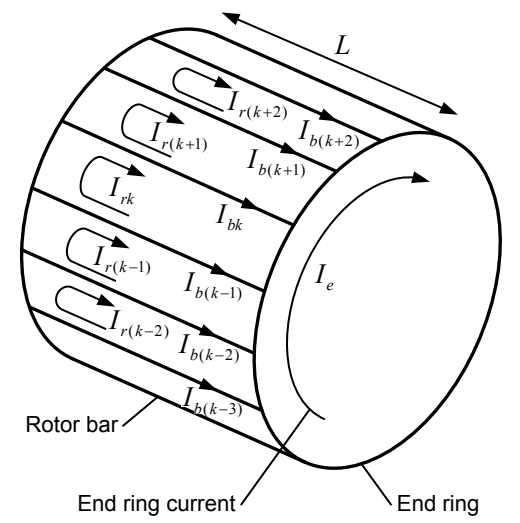

Fig. 1. Elementary rotor loops and current definitions.

The mechanical equation of the machine is:

$$
T_{e m}-T_{L}=J \frac{d \Omega_{m}}{d t}
$$

where $T_{e m}$ is the electromagnetic torque produced by the machine, $T_{L}$ is the load torque, $J$ is the inertia of the rotor and $\Omega_{m}$ is the mechanical speed.

It is also assumed that $i_{f}$ as one of stator phase current, $i_{(1-2 s) f}$ is the arising current due to rotor asymmetry. The expression of $i_{f}$ and $i_{(1-2 s) f}$ are:

$$
\begin{gathered}
i_{f}=I_{f} \cos \left(\omega t-a_{f}\right) \\
i_{(1-2 s) f}=I_{(1-2 s) f} \cos \left((1-2 s) \omega t-a_{(1-2 s) f}\right)
\end{gathered}
$$

where $\omega=2 \pi f$ represents power supply angular frequency; $I_{f}, I_{(1-2 s) f}, a_{f}$, and $a_{(1-2 s) f}$ represent the amplitude and initial phase of $f$ and $(1-2 s) f$ frequency characteristic components respectively.

The fundamental magnetic flux can be expressed as:

$$
\phi(t)=\Phi \cos \left(\omega t-a_{\phi}\right)
$$

where $\Phi$ is magnitude of fundamental magnetic flux, $a_{\Phi}$ is the initial phase of fundamental magnetic flux.

The fundamental current $i_{f}$ interacts with the fundamental magnetic flux $\Phi$ generates torque:

$$
T_{f}=3 P \Phi I_{f} \sin \left(a_{\phi}-a_{f}\right)
$$

where $P$ is the numbers of pole pair.

Under the same rule, the arising current $i_{(1-2 s) f}$ due to broken bars interacts with the fundamental magnetic flux produces an oscillatory torque at frequency $2 s f$ :

$\Delta T_{(1-2 s) f}(t)=3 P \Phi I_{(1-2 s) f} \sin \left(2 s \omega t-\left(a_{\phi}-a_{(1-2 s) f}\right)\right)=$

$=\Delta T_{(1-2 s) f m} \sin \left(2 s \omega t-\left(a_{\phi}-a_{(1-2 s) f}\right)\right)$

The amplitude of torque oscillation is:

$$
\Delta T_{(1-2 s) f m}=3 P \Phi I_{(1-2 s) f}
$$

(7) demonstrates that the fundamental current interacting with supply current generates a constant torque. In contrast to (7), (8) shows $\Delta T_{(1-2 s) f}$ modulated by frequency $2 s \omega$, which leads to speed alternation component $\Delta \omega_{r}(t)$ according to motor rotating theory.

The driving system incremental equation of motion is presented as:

$$
J \frac{d}{d t} \Delta \omega_{r}(t)=\Delta T_{(1-2 s) f}(t)
$$

where $J$ is the combined machine load inertia, $\omega_{r}$ is the rotor rotate speed.

Taking the integration operation, the speed ripples caused by torque oscillation can be expressed as:

$$
\begin{aligned}
& \Delta \omega_{r}(t)=\frac{1}{J} \int \Delta T_{(1-2 s) f}(t) d t= \\
& =-\frac{\Delta T_{(1-2 s) f m}}{2 s J \omega} \cos \left(2 s \omega t-\left(a_{\phi}-a_{(1-2 s) f}\right)\right)
\end{aligned}
$$

The amplitude of speed oscillation is:

$$
\Delta \omega_{r m}=\frac{\Delta T_{(1-2 s) f m}}{2 s J \omega}
$$

Due to rotor asymmetry, the $(1 \pm 2 s) f$ rotor currents generated by the corresponding EMFs produce two rotating fields at frequencies $\pm 3 s f$ and generate same EMF and current. As a consequence, this process gives rise to stator current components at frequencies:

$$
f_{b r b}=(1 \pm 2 k s) f
$$

With the result of previous analysis, oscillation signal distortion happens in current, speed and torque when broken rotor bars faults developed. Moreover, the amplitude of this oscillation depends on the factors of fault extent, operating conditions and the inertia. Therefore, the direct apply FFT to machine stator current under this circumstance seems ineffective.

\section{Discrete wavelet transform}

Discrete wavelet transform (DWT) decomposes a signal by passing it successively through high pass and low pass filters into its approximate and detailed versions using multi resolution analysis (MRA) as seen in [9]. Each step of decomposition of the signal corresponds to a certain resolution.

Fig. 2 shows two level wavelet decompositions. Here $H$ and $L$ are high-pass and low-pass filter respectively. At each level of scaling for various positions, the correlation between signal and wavelet are called wavelet coefficients. High pass filter coefficients are called detailed coefficient $c D_{n}$ and low pass filter coefficients are called approximate coefficients $c A_{n}$.

The first level of decomposition coefficients are $c A_{1}$ and $c D_{1}$, where $c A_{1}$ is the approximate version of the original signal and $c D_{1}$ is the detailed version of the original signal. At each decomposition level, the corresponding detailed and approximate coefficients have definite frequency bandwidths given by $\left[0-f_{s} / 2^{l+1}\right]$ for approximate coefficient $c A_{1}$ and $\left[f_{s} / 2^{l+1}-f_{s} / 2^{l}\right]$ for detailed one $c D_{1}$ where $f_{s}$ is the sampling frequency, $l$ denotes the decomposition level limited by the sampling frequency $f_{s}$, where $f_{s} / 2$ is the corresponding Nyquist frequency. At each step of decomposition the sampled dataset are down-sampling by a factor of $2 \downarrow$, 


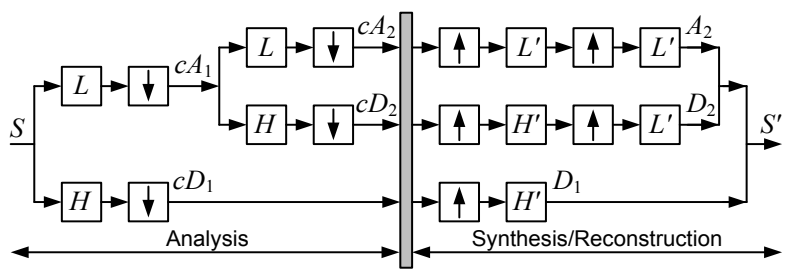

Fig. 2. Wavelet analysis and synthesis of a signal $S$.

which is denoted dyadic decomposition. The spectral frequency bands of different detailed coefficients are shown in the Table 1.

\section{Broken rotor bar fault and quantitative diagnostic approach}

The current component and its oscillation can be related to the fault rate in steady state condition. Characteristic current at frequency $(1 \pm 2 k s) f$ merge in the stator current when rotor asymmetry happens. Among these arisen currents, frequency at $(1 \pm 2 k s) f$ is the most suitable signal used for fault detection and quantitative diagnostic due to the evidently amplitude.

It is known that load level, fault extent are essential elements lead to motor variables variation. However, stator variables are constant values under normal condition and broken bar fault. In this paper, mean absolute value is used to represent the load level. Standard deviation (SD) is used to illustrate the oscillation caused by broken bars. The expression of mean absolute and standard deviation are presented in (14) and (15) and the calculated result shows in Table 3.

$$
\begin{gathered}
\text { meanabs }=\frac{1}{N} \cdot \sum_{i=1}^{N}\left|x_{i}\right| \\
S D=\sqrt{\frac{1}{N} \cdot \sum_{i=1}^{N}\left(\left|x_{i}\right|-\text { meanabs }\right)^{2}}
\end{gathered}
$$

Table 4 shows the values of mean absolute and standard deviation. Mean absolute represents the load variation, while standard deviation is used to represent signal oscillation. The ratio between standard deviation and mean absolute is introduced as an index for induction motor broken bar quantitative diagnostic analysis. The ration of the amplitude of oscillation of stator current and its mean value is presented as:

$$
\text { Index }=\frac{S D}{\text { meanabs }}
$$

where $S D$ represents standard deviation, meanabs represents mean absolute values.

By calculating the fault index (16), it is much easier to diagnose the induction machines condition. As shown in Table 4, under healthy situation this index is around 1.67; when one broken rotor bar occurs, this index will drop to 1.40 . As broken bars number increase, the index will continue drop to 1.36 and 1.31 under two and three broken bars. Table 4 has shown the obvious gap between these indexes.
Table 1. Spectral frequency bands at different decomposition levels

\begin{tabular}{|c|c|}
\hline Decomposition Details & Frequency Bands (Hz) \\
\hline Detail Level 1 & $2048-4096$ \\
\hline Detail Level 2 & $1024-2048$ \\
\hline Detail Level 3 & $512-1024$ \\
\hline Detail Level 4 & $256-512$ \\
\hline Detail Level 5 & $128-256$ \\
\hline Detail Level 6 & $64-128$ \\
\hline Detail Level 7 & $32-64$ \\
\hline Detail Level 8 & $16-32$ \\
\hline Detail Level 9 & $8-16$ \\
\hline Detail Level 10 & $4-8$ \\
\hline
\end{tabular}

Table 2. Specifications of an induction machine

\begin{tabular}{|c|c|}
\hline Specification & Value \\
\hline Rated Power & $3.7 \mathrm{~kW}$ \\
\hline Horse Power & $5 \mathrm{HP}$ \\
\hline Input Voltages & $220 / 380 \mathrm{~V}$ \\
\hline Input Currents & $13.8 / 8.0 \mathrm{~A}$ \\
\hline Pole pairs & 1 \\
\hline Frequency & $50 \mathrm{~Hz}$ \\
\hline Speed & $3000 \mathrm{rpm}$ \\
\hline Number of Stator Slots & $36 \mathrm{EA}$ \\
\hline Number of Rotor Bars & $28 \mathrm{EA}$ \\
\hline
\end{tabular}

\begin{tabular}{|c|c|c|c|}
\hline \multicolumn{4}{|c|}{ Healthy } \\
\hline & No Load & $50 \%$ & $100 \%$ \\
\hline Mean abs & 0.272 & 0.8505 & 1.5923 \\
\hline Standard Deviation & 0.4543 & 1.4313 & 2.677 \\
\hline \multicolumn{4}{|c|}{ One broken bar } \\
\hline & No Load & $50 \%$ & $100 \%$ \\
\hline Mean abs & 0.3235 & 0.9523 & 1.7578 \\
\hline Standard Deviation & 0.4546 & 1.3358 & 2.475 \\
\hline \multicolumn{4}{|c|}{ Two broken bars } \\
\hline & No Load & $50 \%$ & $100 \%$ \\
\hline Mean abs & 0.339 & 1.0028 & 1.8288 \\
\hline Standard Deviation & 0.4641 & 1.3718 & 2.501 \\
\hline \multicolumn{4}{|c|}{ Three broken bars } \\
\hline & No Load & $50 \%$ & $100 \%$ \\
\hline Mean abs & 0.347 & 1.0628 & 1.9135 \\
\hline Standard Deviation & 0.4566 & 1.3964 & 2.513 \\
\hline
\end{tabular}

Table 3. Simulation result analysis based on mean abs and $S D$ values

Table 4. Fault index ratio illustration of induction motor

\begin{tabular}{|c|c|c|c|}
\hline & No Load & $50 \%$ & $100 \%$ \\
\hline Healthy & 1.67022 & 1.68289 & 1.6812 \\
\hline One broken Bar & 1.40525 & 1.4027 & 1.4080 \\
\hline Two Broken Bars & 1.36902 & 1.36796 & 1.3675 \\
\hline Three Broken Bars & 1.31585 & 1.31388 & 1.3133 \\
\hline
\end{tabular}

Table 5. Experiment induction motor fault index ratio

\begin{tabular}{|c|c|c|c|c|}
\hline & No Load & $30 \%$ & $60 \%$ & $100 \%$ \\
\hline Healthy & 1.5 & 1.69 & 1.69 & 1.7 \\
\hline One broken Bar & 1.41 & 1.39 & 1.4 & 1.4 \\
\hline Two Broken Bars & 1.35 & 1.37 & 1.37 & 1.36 \\
\hline Three Broken Bars & 1.32 & 1.33 & 1.32 & 1.33 \\
\hline
\end{tabular}




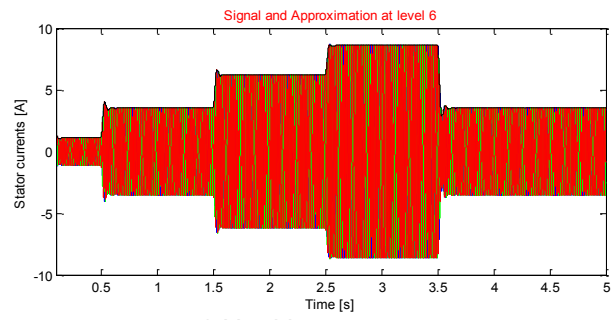

a) Healthy motor

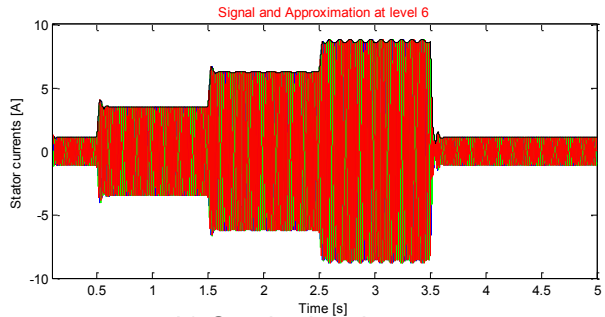

b) One broken bar

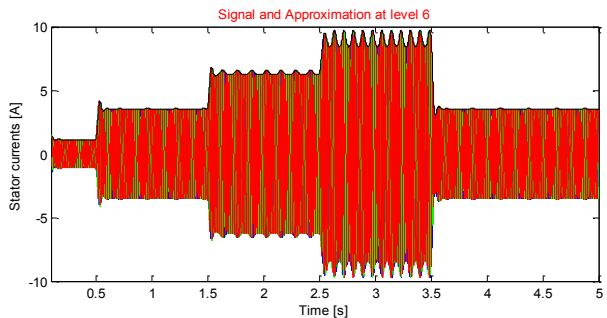

c) Two broken bars

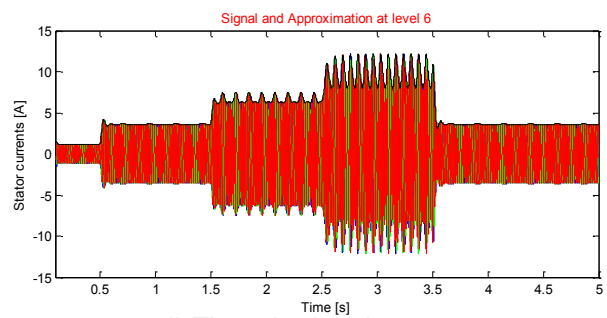

d) Three broken bars

Fig. 3. Experimental results of motor stator current under different load conditions.

\section{Experimental test and results}

The characteristics of the three phase induction machine used in the tests are listed in Table 2. Among these tests, induction machines with healthy, one broken bar, two broken bars and three broken bars under no-load, 30\% load, $60 \%$ load and full load conditions are tested and compared. A current Hall effect sensor is placed in one line wire. The stator current is sampled at $5 \mathrm{kHz}$ rate and transferred to a PC by an ADC-11 acquisition board.

In each experiment, induction machine are start with no load condition for 30 second then $30 \%, 60 \%$ and full load are added and keep running for one minute. The experimental results are shown in Fig. 3(a-d).

Under healthy condition, the indexes are between 1.5-1.7; under one broken bar these values are around 1.4; under two broken bars these values are close to 1.35 , while under three broken bars scenario, these ratios are 1.3 as shown in Table 5 . The results demonstrate the ability of the proposed approach for induction motor broken bar quantitative diagnostic analysis.

\section{Conclusion}

It has been shown that the current components at frequencies $(1 \pm 2 s) f$ can be used for rotor fault diagnosis of an induction machine. The characteristic frequencies are strongly dependent on the load level and fault extent. Following the physical phenomena caused by the failure, simplified relationships linking stator current, speed and torque ripples components have been derived. These relationships allow to recognise the machine reaction on the speed ripple as stator current and fault extent. Therefore, the ratio of the ripple components leads to the computation of the actual broken bar number and can be referred as fault severity without complicated calculation.

\section{References}

[1] A. H. Bonnett, and C. Yung, "Increased efficiency versus increased reliability," IEEE Ind. Appl. Mag., vol. 14, no 1, pp. 29-36, 2008.

[2] P. Zhang, Y. Du, T. G. Habetler, and B. Lu, "A survey of condition monitoring and protection methods for medium-voltage induction motors," IEEE Trans. Ind. Appl., vol. 47, no 1, pp. 34-46, 2011.

[3] S. H. Kia, H. Henao, and G. A. Capolino, "Diagnosis of broken-bar fault in induction machines using discrete wavelet transform without slip estimation," IEEE Tran. Ind. Appl., vol. 45, no 4, pp. 1395-1404, 2009.

[4] A. Stefani, A. Bellini, and F. Filippetti, "Diagnosis of induction machines' rotor faults in time-varying conditions," IEEE Trans. Ind. Electron., vol. 56, no 11, pp. 4548-4556, 2009.

[5] Z. Zhang, Z. Ren, and W. Huang, "Broken rotor bar detection in induction motors via wavelet ridge," IEEE Trans. Energy Convers., vol. 18, pp. 417-423, 2003.

[6] A. Ordaz-Moreno, R. de Jesus Romero-Troncoso, J. A. Vite-Frias, and J. R. Rivera-Gillen, "Automatic online diagnosis algorithm for broken-bar detection on induction motors based on discrete wavelet transform for FPGA implementation," IEEE Trans. Ind. Electron., vol. 55, no 5, pp. 2193-2202, 2008.

[7] J. Cusido, L. Romeral, J. A. Ortega, J. A. Rosero, and A. Garcia Espinosa, "Fault detection in induction machines using power spectral density in wavelet decomposition," IEEE Trans. Ind. Electron., vol. 55, pp. 633-643, 2008.

[8] A. R. Munoz, and T. A. Lipo, "Complex vector model of the squirrel-cage induction machine including instantaneous rotor bar currents," IEEE Trans. Ind. Appl., vol. 35, no 6, pp. 1332-1340, 1999.

[9] J. A. Antonino-Daviu, M. Riera-Guasp, J. Roger-Folch, F. Martinez-Gimenez, and A. Peris, "Application and optimization of the discrete wavelet transform for the detection of broken rotor bars in induction machines," Applied and Computational Harmonic Analysis, vol. 21, no 2, pp. 268-279, 2006. 